\title{
ANALISIS DRUG RELATED PROBLEM'S (DRP'S) PADA PASIEN PEPTIC ULCER, DYSPEPSIA, DAN GASTRITIS DI RUMAH SAKIT PROVINSI NTB
}

\author{
Dedent Eka Bimmahariyanto ${ }^{1 *}$, Annisa Alpian \\ Program studi S1 Farmasi Fakultas Kesehatan Universitas Nahdatul Ulama \\ *: dedenthariyanto@gmail.com
}

\begin{abstract}
ABSTRAK
Peptic ulcer adalah peradangan terbuka yang muncul saat lapisan dalam perut (ulkus gastrik) rusak akibat cairan asam pencernaan, dyspepsia mesrupakan suatu kondisi yang bias menyebabkan rasa tidak nyaman pada perut bagian atas karena penyakit asam lambung atau maag, sedangkan gastritis merupakan peradangan pada lambung akibat asam lambung yang merusak lapisan pelindung dinding lambung. Penelitian ini bertujuan mengetahui kejadian Drug Related Problem's (DRP's) pada pasien peptic ulcer, dyspepsia, dan gastritis di Rumah Sakit Umum Daerah Provinsi NTB. Penelitian ini merupakan penelitian deskriptif dengan pengumpulan data dilakukan secara retrospektif. Pengumpulan data dilakukan dengan metode purposive sampling dengan melihat data rekam medik kesehatan pasien gangguan lambung (peptic ulcer, dyspepsia, dan gastritis) rawat inap RSUD Provinsi NTB tahun 2018-2020, Penelitian dilaksanakan pada bulan Agustus. Setelah dilakukan seleksi dengan kriteria inklusi yang telah ditetapkan didapatkan 34 data yang digunakan sebagai sampel penelitian. Berdasarkan hasil penelitian, dari 34 pasien ditemukan kejadian DRPs Sebanyak 5 pasien dengan kategori ketidaktepatan dosis yang mencakup dosis lebih dijumpai pada pemberian obat omeprazol oral $(14.71 \%)$. Terdapat sebanyak $3(8.82 \%)$ pasien dari 34 pasien yang terdiagnosa gangguan lambung (Peptic Ulcer, Dispepsia, Gastritis) di instalasi rawat inap RSUD Provinsi yang berpotensi mengalami interaksi obat.
\end{abstract}

\section{Kata Kunci: DRP'S. Dyspepsia, Gastritis, Peptic Ulcer}

\section{ABSTRACT}

Peptic ulcer is an open inflammation that occurs when the inner lining of the stomach (gastric ulcer) is damaged by acidic digestive, dyspepsia is a condition that can cause discomfort in the upper stomach due to acid reflux or gastritis, while gastritis is inflammation of the stomach due to acid.This study aims to determine the incidence of DRP's in peptic ulcer, dyspepsia, and gastritis patients at the NTB Provincial General Hospital. This research is a descriptive study using with retrospectively data collection. The data was collected by using purposive sampling method by looking at the medical record data for patients with gastric disorders (peptic ulcer, dyspepsia, and gastritis) inpatient services at the Regional General Hospital of NTB Province in 2018-2020. The study was conducted on August. After selection with inclusion criteria, 34 data were obtained which is used as a research sample. Based on research results, 34 patients found the incidence of DRPs. A total of 5 patients of 34 patients (14.71\%)were in the category of dose inaccuracyomeprazol oral drugs, There 
were 3 of 34 patients (8.82\%) patients diagnosed with gastric disorders (Peptic Ulcer, Dyspepsia, Gastritis) in the inpatient services at at the Regional General Hospital of NTB Province.

\section{Keywords: DRP'S, Dyspepsia, Gastritis, PepticUlcer}

\section{PENDAHULUAN}

Penyakit gangguan lambung merupakan penyakit yang banyak di masyarakat. Penyakit ini meningkat di masyarakat setiap tahunnya. Hal ini di sebabkan gaya hidup yang tidak sehat. Penyakit gangguan lambung disebabkan akibat ketidakseimbangan asam lambung dengan bagian pertahanan mukosa lambung. Penyakit gangguan lambung yang banyak dialami seperti dyspepsia, peptik ulser atau tukak lambung dan gastritis $^{1}$.

Gastritis merupakan salah satu penyakit lambung yang paling banyak diderita masyarakat. Gastritis terdiri dari gastritis akut dan kronis dengan keluhan nyeri di bagian lambung, rasa panas di perut, rasa kembung, mual, kadang-kadang disertai muntah. Biasanya keluhan yang diajukan penderita tersebut ringan dan dapat diatasi dengan mengatur makanan. Pada kondisi tertentu penderita harus mendapatkan perawatan di Rumah Sakit $^{2}$. Pengobatan gastritis bertujuan menghilangkan nyeri, menghilangkan inflamasi dan mencegah terjadinya ulkus lambung dan komplikasi. Pengobatan yang diberikan untuk mengatasi keluhan gastritis seperti obat golongan H2 Blocker, PPI, antasida dan sukralfat. Sampai saat ini pengobatan ditujukan untuk mengurangi asam lambung yakni dengan cara menetralkan asam lambung dan mengurangi sekresi asam lambung. Selain itu pengobatan gastritis juga dilakukan dengan memperkuat mekanisme defensif mukosa lambung dengan obat-obat sitoproteksi ${ }^{1}$.

Pada saat terapi gastritis beberapa kemungkinan terjadinya Drug Related Problems (DRPs). DRPs merupakan beberapa masalah berkaitan dengan pengobatan gastritis. Beberapa DRPs yang ditemukan terkait dengan terapi gangguan lambung adanya indikasi yang yang tidak di obati, mendapat obat tanpa indikasi, dosis berlebihan atau kurang, obat diberikan kurang tepat, terjanya intraksi obat ${ }^{3}$.

Berdasarkan hasil survey 
provinsi NTB gastritis menempati sepuluh besar penyakit terbanyak di puskesmas. Pada tahun 2016 gastritis menempati urutan ke lima dari keseluruhan penyakit terbanyak. Angka ini kemudian meningkat tahun 2017 dengan menempati urutan ke tiga. Peningkatan ini kemungkinan disebabkan oleh perubahan gaya hidup kearah yang negatif seperti konsumsi fast food, junk food, aktivitas fisik kurang, dan faktor stres $^{4}$.

Berdasarkan uraian tersebut yang melatarbelakangi perlunya dilakukan penelitian untuk mengkaji terapi pada penderita gastritis di Provinsi NTB yang kemungkinan terjadi DRPs. Penelitian akan dilakukan di RSUD provinsi NTB karena merupakan rumah sakit rujukan berbagai rumah sakit di NTB.

\section{METODE PENELITIAN}

Penelitian ini termasuk penelitian observasional tau non eksperimental dengan mengikuti rancangan deskriptif serta pengambilan data case series yang bersifat retrospektif dengan menggunakan data rekam medik ${ }^{5}$.
Alat yang digunakan pada penelitian ini adalah lembar pengumpulan data Drug Information Handbook tahun 2009, dan British National Formulary tahun 2011 untuk melihat ketepatan dosis, dan buku acuan Stockley's Drug Interaction tahun 2008, Drug Interaction Facts tahun 2012, dan drug interaction hecker yaitu www.drugs.com, dan www.medscape.com untuk melihat interaksi obat. Bahan yang digunakan pada penelitian ini adalah data rekam medik pasien dengan diagnosa gangguan lambung pada tahun 20182020 yang dimulai dari bulan januari sampai desember. Subyek penelitian `adalah rekamedis pasien dengan diagnosa peptic ulcer, dyspepsia, dan gastritis di rumah Sakit Provinsi NTB yang memenuhu kriteria inklusi.

Populasi pada penelitian ini adalah semua pasien penderita gangguan lambung di Instalasi Rawat Inap Rumah Sakit Privinsi NTB tahun 2018-2020. Sampel diambil menggunakan teknik purposive sampling yang memenuhi kriteria inklusi yang meliputi pasien terdiagnosa penyakit gangguan lambung dengan penyakit penyerta 
yang menjalani rawat inap,

Data di analisis dengan mencocokan dosis obat yang digunakan dengan literature untuk mengetahui ketepatan atau ketidaktepatan dosis yang mencakup dosis kurang dan dosis lebih, serta potensi interaksi obat. Selanjutnya masing-masing hasil dianalisis diklasifikasi dalam bentuk persentase dengan rumus:

$\frac{\text { Total angka kejadian DRPS }}{\text { Total angka kejadian DRPS keseluruhan }} \times 100 \%$

\section{HASIL DAN PEMBAHASAN}

Berdasarkan hasil penelitian pasien yang terdiagnosa mengalami gangguan lambung (Dispepsia, Peptic Ulcer, Gastritis) di Instalasi Rawat Inap Rumah Sakit Provinsi Nusa Tenggara Barat tahun 2018 - 2020. Setelah dilakukan seleksi dengan kriteria inklusi yang telah ditetapkan didapatkan 34 data yang digunakan sebagai sampel penelitian.

\section{A. Karakteristik \\ Pasien Berdasarkan Jenis Kelamin}

Hasil penelitian dengan menggunakan 34 catatan medik mendapatkan jumlah pasien berjenis kelamin laki-laki sebanyak $55.88 \%$ dan pasien dengan jenis kelamin perempuan sebanyak $44.12 \%$. Karakteristik pasien gangguan lambung berdasarkan jenis kelamin dapat dilihat dalam tabel 1 .

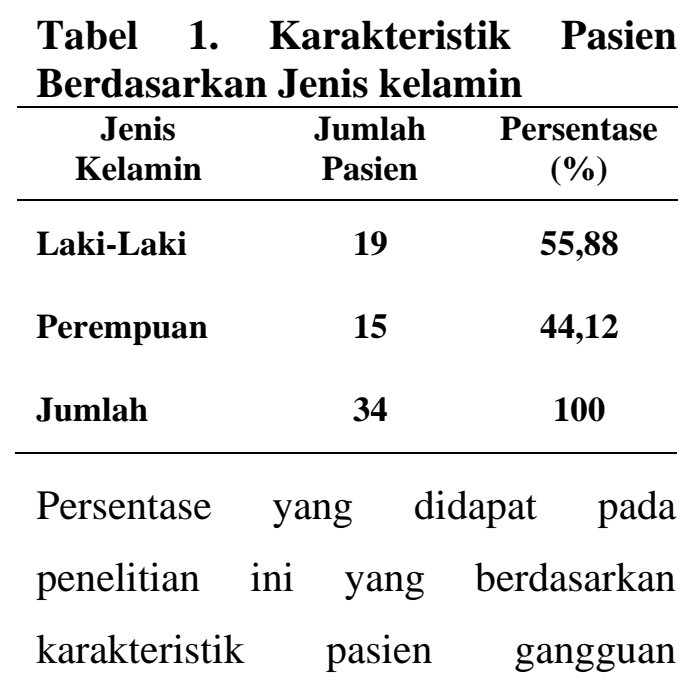
lambung berdasarkan jenis kelamin menunjukkan perbedaan yang signifikan. Pasien dengan jenis kelamin laki-laki lebih banyak menderita gangguan lambung dibandingkan dengan perempuan, hal ini disebabkan karena jenis kelamin laki - laki memiliki resiko lebih besar untuk mengalami ulcer disbanding perempuan, hal ini berkaitan dengan kebiasaan pola hidup dari pasien contohnya merokok yang banyak dilakukan oleh laki - laki.

\section{B. Karakteristik \\ Pasien Berdasarkan Usia}

Data hasil penelitian yang dikumpulkan dengan melihat 
karakteristik pasien berdasarkan usia pasien gangguan lambung diketahui terbanyak pada rentang usia di atas 45 tahun dengan nilai persentase $82,35 \%$ dengan jumlah 28 pasien. Karakteristik pasien berdasarkan usia selengkapnya dapat dilihat pada tabel 2.

Tabel 2. Karakteristik Pasien Berdasarkan Usia

\begin{tabular}{|c|c|c|}
\hline \multirow[t]{2}{*}{ Usia } & Jumlah & Persentase (\%) \\
\hline & Pasien & \\
\hline $15-24$ & 2 & 5,88 \\
\hline $25-44$ & 4 & 11,76 \\
\hline$>45$ & 28 & 82,35 \\
\hline Jumlah & 34 & 100 \\
\hline
\end{tabular}

Pada rentang usia $>45$ tahun, sering terjadi, hal ini dikarenakan adanya penurunan sistem kerja lambung dan dimungkinkan akiba dari peningkatan OAINS pada pasien usia lanjut ${ }^{6}$.

\section{Karakteristik Berdasarkan Diagnosis \\ Pasien}

Penelitian yang berdasarkan diagnosis ditentukan dari diagnosa yang diberikan dokter kepada pasien gangguan lambung rawat inap. Diagnosis yang banyak ditemukan adalah gastritis sebanyak 47,06\% dengan jumlah pasien 16. Data selanjutnya dapat dilihat di tabel 3.

Tabel 3. Karakteristik Diagnosis

\begin{tabular}{ccc}
\hline Diagnosa & Jumlah & \begin{tabular}{c} 
Persentase \\
\cline { 2 - 3 }$(\%)$
\end{tabular} \\
\cline { 2 - 3 } $\begin{array}{c}\text { Peptic } \\
\text { Ulcer }\end{array}$ & 11 & 32,35 \\
\hline Gastritis & 16 & 47,06 \\
\hline Dispepsia & 7 & 20,59 \\
\hline Jumlah & 34 & 100 \\
\hline \multicolumn{2}{l}{$\begin{array}{l}\text { D. Karakteristik } \\
\text { Berdasarkan Penyakit Utama }\end{array}$}
\end{tabular}

Data penelitian yang berdasarkan diagnosis ditentukan dari diagnosa utama pasien gangguan lambung di rawat inap. Diagnosis yang banyak ditemukan adalah CHF sebanyak $3,74 \%$ dengan jumlah pasien 8 . Data selanjutnya dapat dilihat di tabel 4.

Tabel 4. Karakteristik Penyakit Utama

\begin{tabular}{ccc}
\hline \multirow{2}{*}{ Diagnosa } & Jumlah & $\begin{array}{c}\text { Persentase } \\
(\%)\end{array}$ \\
\cline { 2 - 2 } & Pasien & 2,94 \\
\hline $\begin{array}{c}\text { Cushing } \\
\text { Syndrome }\end{array}$ & 1 & 8,82 \\
\hline CHF & 3 & 3,74 \\
\hline Melena & 8 & 1,36 \\
\hline HT & 4 & 0,34 \\
\hline TB & 1 & 0,34 \\
\hline Sepsis & 1 & 0,34 \\
\hline SNH & 1 & 17,65 \\
\hline Anemia & 6 & $\mathbf{3 6}$ \\
\hline Jumlah & $\mathbf{2 8}$ &
\end{tabular}

Tabel di atas merupakan data dari penyakit utama pada kasus gangguan lambung di RSUP NTB. Yang dimana penyakit utama tersebut salah satu menjadi pemicu dari munculnya gangguan lambung. 


\section{KaraktristikObat}

Karakteristik obat pada Tabel. 5 digunakan untuk mengetahui gambaran peresepan pasien dengan diagnose penyakit gangguan lambung di Instalasi Rawat Inap Berdasarkan hasil penelitian obat gangguan lambung yang paling banyak diresepkan yaitu omeprazole $(6,80 \%)$ dari 20 pasien yang merupakan obat golongan PPI. Proton Pump Inhibitor (PPI) adalah salah satu kelas terapi yang paling sering diresepkan karena dianggap memiliki efek kemajuan yang begitu besar dalam pengobatan penyakit asam lambung ${ }^{7}$.

\section{Tabel 5. Karakteristik Terapi Pasien}

\begin{tabular}{cccc}
\hline Penyakit & Terapi & Jumlah & \multirow{2}{*}{$\%$} \\
\cline { 3 - 3 } & Pasien & \\
\hline $\begin{array}{c}\text { Dispepsia, } \\
\text { gastritis, } \\
\text { peptic } \\
\text { ulcer }\end{array}$ & Ondansentron & 13 & 4,42 \\
\hline $\begin{array}{c}\text { peptic } \\
\text { ulcer }\end{array}$ & Ranitidin & 8 & 2,72 \\
\hline $\begin{array}{c}\text { Syndrome } \\
\text { Chusing }\end{array}$ & Ceftriaxone & 8 & 2,72 \\
\hline $\begin{array}{c}\text { Syndrome } \\
\text { Chusing, } \\
\text { dispepsia }\end{array}$ & Fucoidan & 1 & 0,34 \\
\hline $\begin{array}{c}\text { Syndrome } \\
\text { Chusing, } \\
\text { dispepsia }\end{array}$ & Aspar K & 1 & 0,34 \\
\hline $\begin{array}{c}\text { Syndrome } \\
\text { Chusing, } \\
\text { dispepsia }\end{array}$ & Arcoxia & 1 & 0,34 \\
\hline $\begin{array}{c}\text { Syndrome } \\
\text { Chusing, } \\
\text { dispepsia }\end{array}$ & Provely & 1 & 0,34 \\
\hline \begin{tabular}{c} 
CHF \\
\hline
\end{tabular} & Bisoprolol & 2 & 0,68 \\
\hline
\end{tabular}

\begin{tabular}{|c|c|c|c|}
\hline $\begin{array}{c}\mathrm{CHF}, \\
\text { gastritis }\end{array}$ & Landesartan & 1 & 0,34 \\
\hline $\begin{array}{c}\text { CHF, } \\
\text { gastritis }\end{array}$ & Spironolakton & 1 & 0,34 \\
\hline $\begin{array}{c}\mathrm{CHF}, \\
\text { gastritis }\end{array}$ & Simar & 1 & 0,34 \\
\hline \multirow[t]{2}{*}{ Nyeri } & $\begin{array}{c}\text { As. } \\
\text { Mefenamat }\end{array}$ & 1 & 0,34 \\
\hline & Cefadroxil & 1 & 0,34 \\
\hline Gastritis & Lansoprazol & 5 & 1,70 \\
\hline $\begin{array}{c}\text { Dispepsia, } \\
\text { gastritis, } \\
\text { peptic } \\
\text { ulcer }\end{array}$ & Sucralfat & 14 & 4,76 \\
\hline $\begin{array}{l}\text { Peptic } \\
\text { Ulcer }\end{array}$ & Tranexamat & 3 & 1,02 \\
\hline $\begin{array}{c}\text { Dispepsia, } \\
\text { gastritis, } \\
\text { peptic } \\
\text { ulcer }\end{array}$ & Omeprazole & 20 & 6,80 \\
\hline \multirow[t]{5}{*}{ HT } & Amlodipin & 3 & 1,02 \\
\hline & Citicolin & 4 & 1,36 \\
\hline & Betahistamin & 1 & 0,34 \\
\hline & Valsartan & 1 & 0,34 \\
\hline & Vit. K & 3 & 1,02 \\
\hline \multirow[t]{2}{*}{$\begin{array}{c}\text { Dispepsia, } \\
\text { gastritis, } \\
\text { peptic } \\
\text { ulcer }\end{array}$} & Antasida & 3 & 1,02 \\
\hline & Jumlah & 97 & 33 \\
\hline
\end{tabular}

\section{Analisis Drug Related Problems Kategori Dosis}

Menurut $^{8}$ dalam penelitian Dini Perwita adalah salah satu problem terapi dengan obat yaitu ketidak tepatan dosis obat, bisa dikarenakan dosis yang terlalu rendah atau terlalu tinggi. Kemungkinan penyebab problem terapi dengan obat terkait dosis yaitu interval pemakaian yang terlalu jarang atau sering, dosis terlalu rendah atau berlebih untuk mencapai 
efek yang diinginkan, dan durasi obat yang terlalu pendek atau panjang.

Pada evalausi ketepatan dosis ini diukur menggunakan standar terapi dari Drug Information Handbook edisi 17th evaluasi ketepatan dosis penggunaan obat ganguan lambung pada pasien rawat inap sebanyak 34 pasien dapat dilihat pada tabel 6 .

Tabel 6. Distribusi Ketepatan Penggunaan Dosis

\begin{tabular}{|c|c|c|c|}
\hline \multirow{2}{*}{ Terapi } & \multicolumn{3}{|c|}{ Kesesuaian Dosis } \\
\hline & Keterangan & Jumlah & $\%$ \\
\hline Ranitidin iv & Sesuai & 8 & 23,53 \\
\hline $\begin{array}{c}\text { Ranitidin } \\
\text { oral }\end{array}$ & Sesuai & 1 & 2,94 \\
\hline $\begin{array}{c}\text { Lansoprazol } \\
\mathrm{e} \\
\end{array}$ & Sesuai & 5 & 14,71 \\
\hline $\begin{array}{c}\text { Sucralfat } \\
\text { oral }\end{array}$ & Sesuai & 14 & 41,12 \\
\hline Antasida & Sesuai & 3 & 8,82 \\
\hline $\begin{array}{c}\text { Omeprazole } \\
\text { iv } \\
\end{array}$ & Sesuai & 11 & 32,35 \\
\hline $\begin{array}{c}\text { Omeprazole } \\
3 \times 40 \mathrm{mg}\end{array}$ & $\begin{array}{c}\text { Dosis } \\
\text { berlebih }\end{array}$ & 5 & 14,71 \\
\hline $\begin{array}{c}\text { Omeprazole } \\
1 \times 20 \mathrm{mg}\end{array}$ & Sesuai & 1 & 2,94 \\
\hline
\end{tabular}

Berdasarkan hasil analisis, didapatkan hasil untuk ketepatan dosis sebanyak 29 kasus dengan persentase 85,29\% dan ketidaktepatan dosis sebanyak 5 kasus dengan persentase $14,71 \%$. Berdasarkan Tabel. 6 ketidaktepatan pemberian dosis obat berupa dosis lebih dijumpai pada pemberian obat omeprazol oral $(14,71 \%)$. Dan yang lainnya sudah sesuai dengan standar penggunaan obat. Menurut $^{9}$ penggunaan dosis obat dibawah dosis obat yang digunakan melebihi dosis standar (dosis lebih), penggunaan dosis yang melebihi dosis standar akan mengakibatkan toksisitas dari obat tersebut meningkat.

\section{Analisis Drug Related Problems Kategori Interaksi Obat.}

Terdapat sebanyak $3(8,82 \%)$ pasien dari 34 pasien yang terdiagnosa gangguan lambung (Peptic Ulcer, Dispepsia, Gastritis) di instalasi rawat inap Rumah Sakit Umum Daerah Provinsi yang berpotensi mengalami interaksi obat.

Tabel 7. Distribusi Interaksi Obat

\begin{tabular}{|c|c|c|c|c|}
\hline Obat A & $\begin{array}{l}\text { Obat } \\
\text { B }\end{array}$ & $\begin{array}{c}\text { Interaksi } \\
\text { Obat }\end{array}$ & $\sum_{\text {Pasien }}^{\sum}$ & $\%$ \\
\hline Ranitidin & PCT & Minor & 1 & 2,94 \\
\hline $\begin{array}{c}\text { Lansopra } \\
\text { zole }\end{array}$ & $\begin{array}{c}\text { Sucralf } \\
\text { at }\end{array}$ & Moderate & 2 & 5,88 \\
\hline
\end{tabular}

keparahan minor terjadi interaksi antara ranitidin dengan parasetamol. Dalam penelitiannya ${ }^{10}$ ranitidin dapat menghambat enzim glucoronyltransferase parasetamol, namun potensi interaksi yang terjadi tidak bermakna secara klinis ${ }^{11}$.

Sedangkan interaksi obat yang paling sering terjadi dengan tingkat keparahan moderate yaitu interaksi 
antara omeprazol dengan furosemid. Penggunaan obat golongan PPI jangka panjang dapat menyebabkan hipomagnesia, dan furosemid dapat menyebabkan meningkatnya efek hipomagnesia dari omeprazol ${ }^{12}$.

\section{KESIMPULAN}

Dari hasil evaluasi pada penelitian ini dapat disimpulkan bahwa ketepatan penggunaan obat pada pasien gangguan lambung (gastritis, dyspepsia, peptic ulcer) rawat inap di Rumah Sakit Umum Daerah Provinsi NTB periode 20182019 kejadian drug related problems atau masalah yang berkaitan dengan obat sebanyak 5 kasus dengan persentase $14,71 \%$ untuk kategori ketidaktepatan dosis dengan pemberian dosis yang berlebih. Untuk yang berpotensi mengalami interaksi obat terdapat sebanyak $3(8,82 \%)$ pasien dari 34 pasien, yang ditemukan adanya interaksi minor dan moderate pada penggunaannya.

\section{UCAPAN TERIMA KASIH}

Terimakasih disampaikan kepada semua pihak yang telah membantu terlaksananya penelitian ini. Terimakasih kami sampaikan seluruh pihak Universitas Nahdlatul Ulama NTB dan Direktorat Riset dan Pengabdian Masyarakat Direktorat Jenderal Riset dan Pengembangan Kementerian Riset, Teknologi, dan Pendidikan Tinggi.

\section{DAFTAR PUSTAKA}

1) Dipiro, J.T, Robert, L.T, Gary, C.Y, Gary, R.M., Barbara, G.W, Michael Posey, 2008, Pharmacotherapy; A pathophysiological approach, Seventh Edition, McGraw Hill Companie.

2) Sanusi I.A., 2011, Buku Ajar Gatroenterologi, Edisi Kesatu., Interna Publishing Pusat Penerbitan Ilmu Penyakit Dalam, Jakarta Pusat.

3) Setiawati, A. 2007. Farmakologi dan Terapi Edisi 5. Fakultas UI. Jakarta.

4) Dinas Provinsi NTB, 2017. Profile kesehatan provinsi NTB 2017.

5) Lapau, B., 2012, Metode Penelitian Kesehatan: Metode Ilmiah Penulisan Skripsi, Tesis dan Disertasi, yayasan Pustaka Obor Indonesia, Jakarta, pp. 40,47, 51,52.

6) Berardi R.R. \& Welage L.S., 2008, Pharmacotherapi: A Pathophysiologic Approach, dalam Gastrointestinal Disorders, Mc-GrawHill, New York, pp. 569-583.

7) Vanderhoff B.T. and Tahboub R.M., 2002, Proton pump inhibitors: An update, American Family Physician, 66 (2), 273278. 
8) Priyanto, 2008, Farmakoterapi dan Terminologi Medis, Lembaga Studi dan Konsultasi Farmakologi (LESKONFI), Depok.

9) Halczli A. and Woolley A.B., 2013, Medication Underdosing and Underprescribing: important issues that may contribute to polypharmacy and poor outcomes, Formulary Journal Outcomes, 1-4.

10) Baxter K., 2008, Stocley's Drug Interaction, Eighth Edition., Pharmaceutical Press, London.

11) J. Richard, Saad. MD, et.al., 2014, First Line Treatment Strategies For Helicobacter pylori Infection, Departement of Internal Medicine Devision of Gastroenterology University of Michigan Health System Ann. Arbor.

12) Food and Drug Administration, 2011, FDA Drug Safety Communication: Low magnesium levels can be associated with long-term use of Proton Pump Inhibitor drugs (PPIS), U.S. Department of Health and Human Services. 